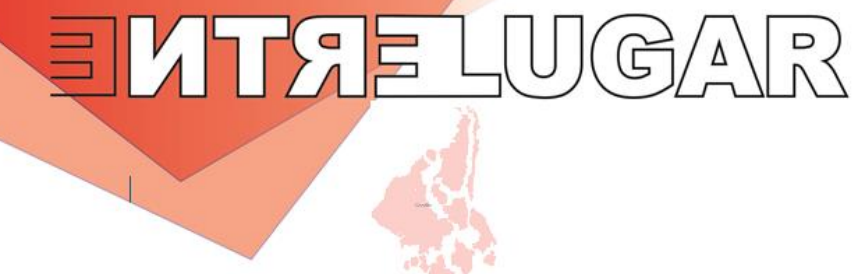

\title{
O PAPEL DO PRONAF NA DINÂMICA GEOECONÔMICA DOS AGRONEGÓCIOS DO OESTE CATARINENSE
}

\section{THE ROLE OF PRONAF IN THE GEOECONOMIC DYNAMICS OF WEST CATARINENSE}

\section{EL PAPEL DEL PRONAF EN LA DINÁMICA GEOECONÓMICA DE LOS AGRONEGOCIOS DEL OESTE CATARINENSE}

\section{Eduardo von Dentz}

Mestre em Geografia pela Universidade Estadual do Oeste do Paraná (Unioeste) campus Francisco Beltrão. Doutorando em Geografia na Universidade Federal de Santa Catarina (UFSC)

eduardovondentz@hotmail.com

\section{Pierre Alves Costa}

Doutor em História pela Universidade Federal Fluminense (2009). Docente na Universidade Estadual do Centro-Oeste, Unicentro - Guarapuava (PR)

alvespierre75@hotmail.com

\section{RESUMO}

No período 2003-2014 o papel das políticas públicas foi fundamental para alavancar diferentes setores sociais e econômicos no Brasil. No campo dos agronegócios, o Pronaf se mostrou a mais eficiente e importante política pública de crédito subsidiado da agricultura de pequena escala da história do Brasil. A partir do Pronaf, os pequenos agricultores puderam acessar recursos indispensáveis para o desenvolvimento das atividades produtivas ligadas a agropecuária. Neste sentido, a região Oeste catarinense, recorte espacial desse artigo, foi uma das mais beneficiadas pelo Pronaf, haja vista que se trata de uma região caracterizada, desde a sua ocupação, por uma agricultura de pequena escala. O objetivo do presente artigo é desvendar o papel do Pronaf no progresso técnico e na dinâmica geoeconômica dos agronegócios da região Oeste catarinense. Para alcançar esse objetivo, metodologicamente, usou-se de três passos: 1) levantamento bibliográfico, 2) levantamento de dados e 3) organização e análise dos dados relacionando-os com a bibliografia levantada.

Palavras chave: Agronegócios; Progresso técnico; Pronaf; Oeste catarinense.

\footnotetext{
ABSTRACT

In the period 2003-2014 the role of public politics was fundamental to in leveraging different social and economic sectors in Brazil. In the field of agribusiness, Pronaf proved to be the most efficient and important public subsidized credit politic for small-scale agriculture in the history of Brazil. From Pronaf, small farmers were able to access indispensable resources for the development of productive activities related to agriculture. In this sense, the western region of
} 




Santa Catarina, a spatial section of this article, was one of the most benefited by Pronaf, since it is a region characterized since its occupation by small-scale agriculture. The objective of this paper is to unveil Pronaf's role in the technical progress and geoeconomic dynamics of agribusiness in the western region of Santa Catarina. To achieve this objective, methodologically, used three steps: 1) bibliographic survey, 2) data collection and 3) data organization and analysis relating them to the surveyed bibliography

Key words: Agribusiness; Technical progress; Pronaf; West of Santa Catarina.

\section{RESUMEN}

En el periodo 2003 hasta 2014 la función de las políticas públicas fue fundamental para desarrollar distintos sectores sociales y económicos de Brasil. En el campo de los agronegocios, el Pronaf se muestro la más eficiente e importante política pública de crédito subsidiado de la agricultura de pequeña escala de la historia de Brasil. Desde el Pronaf, los pequeños agricultores pudieron acezar recursos indispensables para el desarrollo de las actividades productivas ligadas a la agropecuaria. En este sentido, la región Oeste catarinense, delimitación espacial del presente artículo, fue una de las más beneficiadas por el Pronaf, porque se trata de una región caracterizada, desde su ocupación, por una agricultura de pequeña escala. El objetivo del presente articulo es desentrañar el papel del Pronaf en el progreso técnico y en la dinámica geoeconómica de los agronegocios de la región Oeste catarinense. Para lograr ese objetivo, metodológicamente, usose de tres procedimientos: 1) levantamiento bibliográfico, 2) levantamiento de datos y 3) organización y análisis de los datos relacionando los mismos con la bibliografía levantada.

Palabras clave: Agronegocios; Proceso técnico; Pronaf; Oeste catarinense.

\section{INTRODUÇÃO}

A mesorregião Oeste catarinense, conforme classificação do IBGE, é composta por 118 munícipios ${ }^{1}$. No mapa 1 é possível observar a localização geográfica da mesorregião, a divisão municipal e a localização de suas principais cidades.

\footnotetext{
${ }^{1}$ Abelardo Luz, Água Doce, Águas de Chapecó, Águas Frias, Alto Bela Vista, Anchieta, Arabutã, Arroio Trinta, Arvoredo, Bandeirante, Barra Bonita, Belmonte, Bom Jesus, Bom Jesus do Oeste, Caçador, Caibi, Calmon, Campo Erê, Capinzal, Catanduvas, Caxambu do Sul, Chapecó, Concórdia, Cordilheira Alta, Coronel Freitas, Coronel Martins, Cunha Porã, Cunhataí, Descanso, Dionísio Cerqueira, Entre Rios, Erval Velho, Faxinal dos Guedes, Flor do Sertão, Formosa do Sul, Fraiburgo, Galvão, Guaraciaba, Guarujá do Sul, Guatambu, Herval d'Oeste, Ibiam, Ibicaré, Iomerê, Ipira, Iporã do Oeste, Ipuaçu, Ipumirim, Iraceminha, Irani, Irati, Itá, Itapiranga, Jaborá, Jardinópolis, Joaçaba, Jupiá, Lacerdópolis, Lajeado Grande, Lebon Régis, Lindóia do Sul, Luzerna, Macieira, Maravilha, Marema, Matos Costa, Modelo, Mondaí, Nova Erechim, Nova Itaberaba, Novo Horizonte, Ouro, Ouro Verde, Paial, Palma Sola, Palmitos, Paraíso, Passos Maia, Peritiba, Pinhalzinho, Pinheiro Preto, Piratuba, Planalto Alegre, Ponte Serrada, Presidente Castelo Branco, Princesa, Quilombo, Rio das Antas, Riqueza, Romelândia, Saltinho, Salto Veloso, Santa Helena, Santa Terezinha do Progresso, Santiago do Sul, São Bernardino, São Carlos, São
} 
Mapa 1: Localização geográfica da mesorregião Oeste catarinense e suas principais cidades.

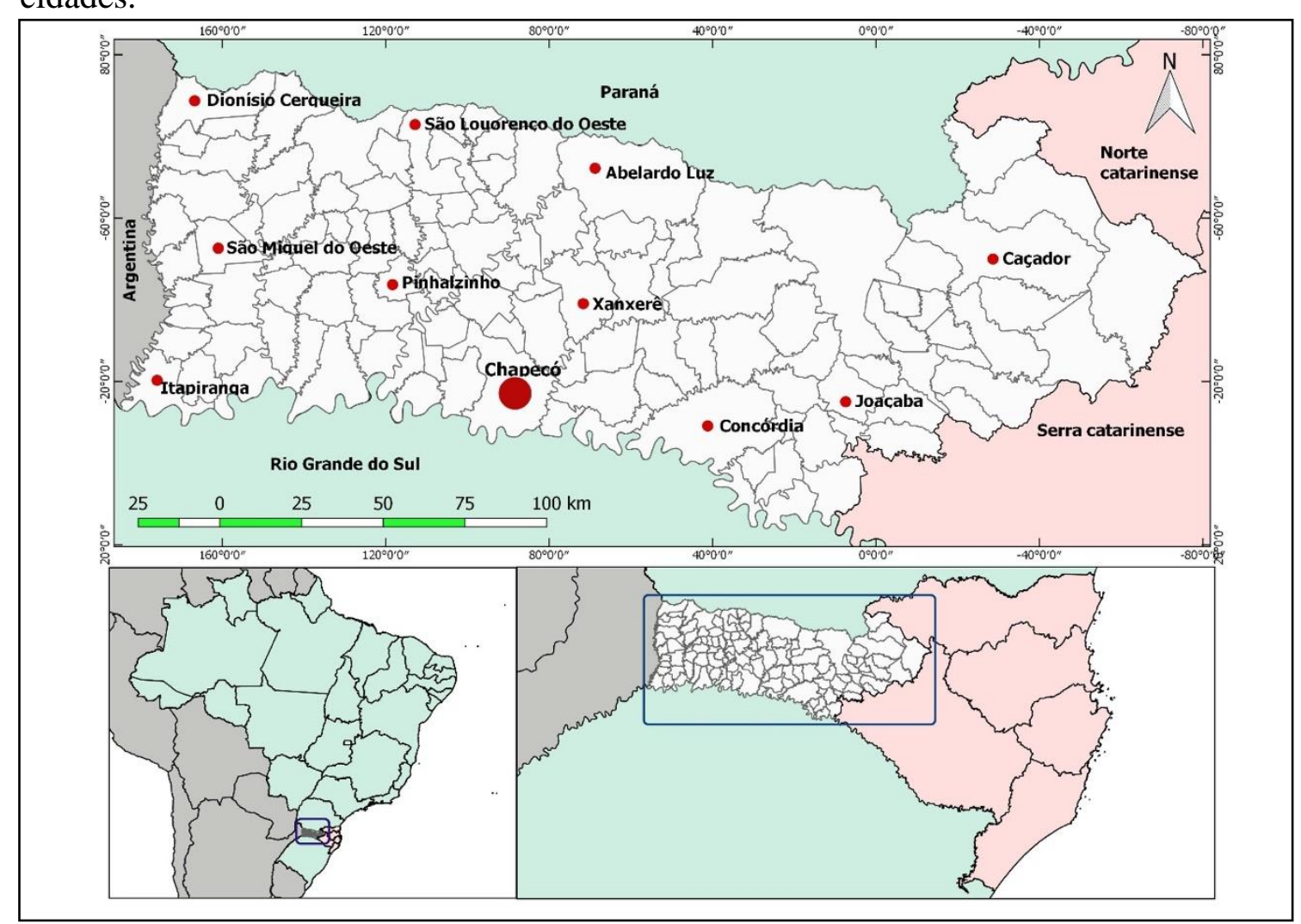

Fonte: Base cartográfica do IBGE.

A caracterização do Oeste catarinense permite apontar que além das atividades ligadas à agropecuária - os agronegócios - que se configuram na atenção central desse artigo, e como importante setor econômico-social da mesorregião, outros setores econômicos vem se destacando mais recentemente, como o metal-mecânico, o setor de logística, de tecnologia e telecomunicações, os segmentos de madeira, móveis e fabricação de papel celulose. Contudo, segundo dados do IBGE (2010), o setor de serviços tem demonstrado forte crescimento nos últimos anos, tendo alcançado $55 \%$ na participação do PIB da mesorregião. Neste sentido, em que pese a importância econômica do setor de serviços para a região, a análise desse artigo estará centrada nos agronegócios.

Em termos gerais, atualmente a mesorregião Oeste catarinense possui uma população que ultrapassa os 1,2 milhões de habitantes (IBGE, 2010), o que representa

Domingos, São João do Oeste, São José do Cedro, São Lourenço do Oeste, São Miguel da Boa Vista, São Miguel do Oeste, Saudades, Seara, Serra Alta, Sul Brasil, Tangará, Tigrinhos, Treze Tílias, Tunápolis, União do Oeste, Vargeão, Vargem Bonita, Videira, Xanxerê, Xavantina e Xaxim. 
cerca de $20 \%$ da população total do estado de Santa Catarina ${ }^{2}$. Desse total, considerando uma média estabelecida para toda a região, pode-se afirmar que em torno de $75 \%$ da população vive nas cidades. Em algumas cidades como Chapecó, Xanxerê, Pinhalzinho, dentre outras, essa porcentagem ultrapassa os $90 \%$. Já do ponto de vista econômico, o Oeste catarinense foi responsável, em 2010, por 19,2\% do Produto Interno Bruto (PIB) de Santa Catarina. A renda per capita da mesorregião é de $\mathrm{R} \$ 20,5$ mil, o que significa, das seis mesorregiões de SC, a terceira melhor renda per capita do estado, ficando atrás somente do Norte catarinense e do Vale do Itajaí (IBGE, 2010).

Nos agronegócios, o Oeste catarinense apresentou forte crescimento na produção de grãos, tendo passado de 500 mil toneladas produzidas em 1940 para 3,3 milhões de toneladas em 1980. Numa média geral, o Oeste catarinense produz cerca de $74 \%$ do total estadual de trigo, $75 \%$ do total estadual de soja, $72 \%$ do total estadual de milho e 53\% do total estadual de feijão (Epagri/Cepa, 2018). Dessa forma, nota-se que a região concentra a produção estadual de grãos, sendo que o mesmo ocorre para os agronegócios de proteína animal (suínos, frangos e leite) (Von Dentz e Espíndola, 2019). Dessa forma, ao mesmo tempo em que se pode dizer que o Oeste catarinense concentra grande parte da produção estadual de alimentos, também é válido afirmar que ocorreu uma diversificação da produção, pois tratam-se de diferentes segmentos de agronegócios nos quais a região se destaca. Junto do crescimento da produção de grãos e animais, ocorreu um forte processo de implantação de pequenos frigoríficos, laticínios, armazéns e processadores de grãos, visando melhor aproveitamento da produção e a venda dos produtos "prontos". Em meio aos avanços obtidos na região, sobretudo no segmento de alimentos, é preciso destacar o importante papel das políticas públicas no financiamento do crescimento ocorrido. Dentre as principais, pode-se citar o Programa Nacional de Fortalecimento da Agricultura Familiar (PRONAF).

Portanto, o objetivo desse artigo é desvendar o papel do Pronaf no progresso técnico e na dinâmica geoeconômica dos agronegócios do Oeste catarinense. Metodologicamente, usou-se de três etapas: 1) levantamento bibliográfico, 2)

\footnotetext{
${ }^{2} \mathrm{Na}$ mesorregião Oeste catarinense, apenas o município de Chapecó ultrapassa os 100 mil habitantes, com pouco mais de 216 mil. Entre 70 mil e 100 mil habitantes, aparecem Caçador e Concórdia. Entre 40 mil e 70 mil habitantes aparecem São Miguel do Oeste, Videira e Xanxerê. Entre 20 mil e 40 mil habitantes aparecem Fraiburgo, Herval d'Oeste, Joaçaba, Maravilha, São Lourenço do Oeste e Xaxim. Os demais municípios possuem população ainda menor, sendo que a grande maioria fica abaixo dos 10 mil habitantes.
} 
levantamento de dados (IBGE, EPAGRI/CEPA) e 3) organização e análise dos dados relacionando-os com a bibliografia levantada. Ademais, visando atender ao objetivo do artigo, além dessa introdução, dividiu-se o artigo em três partes: a primeira aborda sobre o processo de ocupação do Oeste catarinense e sua relação com os agronegócios; a segunda parte aborda sobre o papel do Pronaf na geoeconomia e no progresso técnico dos agronegócios da região e na terceira parte estão as considerações finais.

\section{PROCESSO DE OCUPAÇÃO DO OESTE CATARINENSE E SUA RELAÇÃO COM OS AGRONEGÓCIOS}

Diferentemente da ocupação ocorrida na região serrana e do litoral catarinense, a ocupação da região Oeste do estado está vinculada ao Rio Grande do Sul. Para fazer essa diferenciação, Peluso Jr. (1991) aponta que do ponto de vista natural, o território catarinense pode ser caracterizado por apresentar um altiplano levemente inclinado na sua porção Oeste e uma área que se desdobra numa borda do planalto até o mar, na sua porção Leste. Já do ponto de vista humano, Peluso Jr. (1991) aponta para quatro principais etapas para explicar a ocupação do território do estado de SC. A primeira etapa, datada de meados do século XVII, ocorreu com a chegada dos Vicentistas paulistas, que entraram pelo Norte e foram em direção ao Sul do estado. No mesmo período ocorreu outra corrente de ocupação nas áreas de planalto, deslocando-se para os campos meridionais - região de Lages, com a instalação de grandes fazendas de gado, que usavam os índios como peões, associando relações feudais de propriedade e de trabalho (Mamigonian, 1999).

A segunda etapa de povoamento ocorreu em núcleos esparsos, no século XVIII, no litoral do estado. Essa etapa é marcada pelo sistema de colonização que contou com casais açorianos e madeireiros, cuja influência no litoral catarinense dos açorianos, configurou-se na maior intervenção geopolítica e geoeconômica do governo de Portugal no Sul do Brasil. Os açorianos eram fortes na produção agrícola, de modo que exportaram grandes quantidades de farinha de mandioca para a Europa (Mamigonian, 1999).

A terceira etapa ocorreu a partir de 1820 , com as colônias de povoamento alemã próximas de Rio Negro e São Pedro de Alcântara. No mesmo período, prosperaram também as colônias alemãs de Dona Francisca e a de Blumenau, no médio vale do rio 
Itajaí-Açu. Nesta etapa, também se encontram as colônias italianas que se instalaram no Sul do estado, nos arredores de Criciúma, na segunda metade do século XIX.

A quarta e última etapa de povoamento refere-se à ocupação do Oeste do estado, ocorrida do início até a quarta década do século XX, momento em que empresas colonizadoras de capital comercial nacional e internacional intensificaram a venda de lotes de terras no Oeste catarinense para imigrantes italianos e alemães vindos do estado do Rio Grande do Sul (Espíndola, 2016). Neste sentido, após o período de comercialização das terras, nas décadas de 1930, 1940 e 1950, intensificou-se na região a derrubada da mata, que possibilitou o aproveitamento comercial da madeira, exportada para outros países da América do Sul, sobretudo para a Argentina, além da extração da erva-mate, outra atividade econômica importante para o período (Pertile, 2008). No mapa 2 pode-se visualizar as quatro etapas de povoamento supramencionadas. 


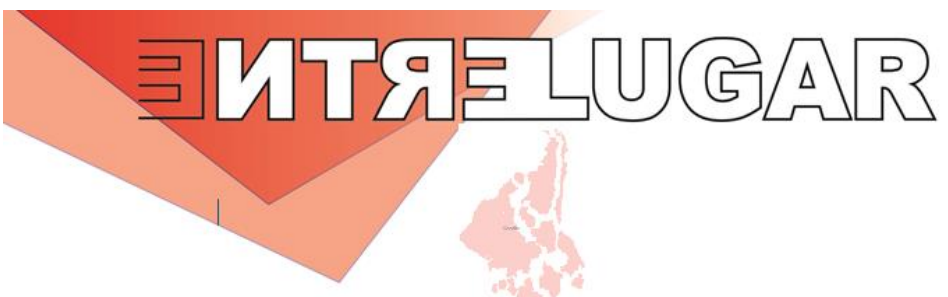

Mapa 2: Etapas de ocupação do estado de Santa Catarina.

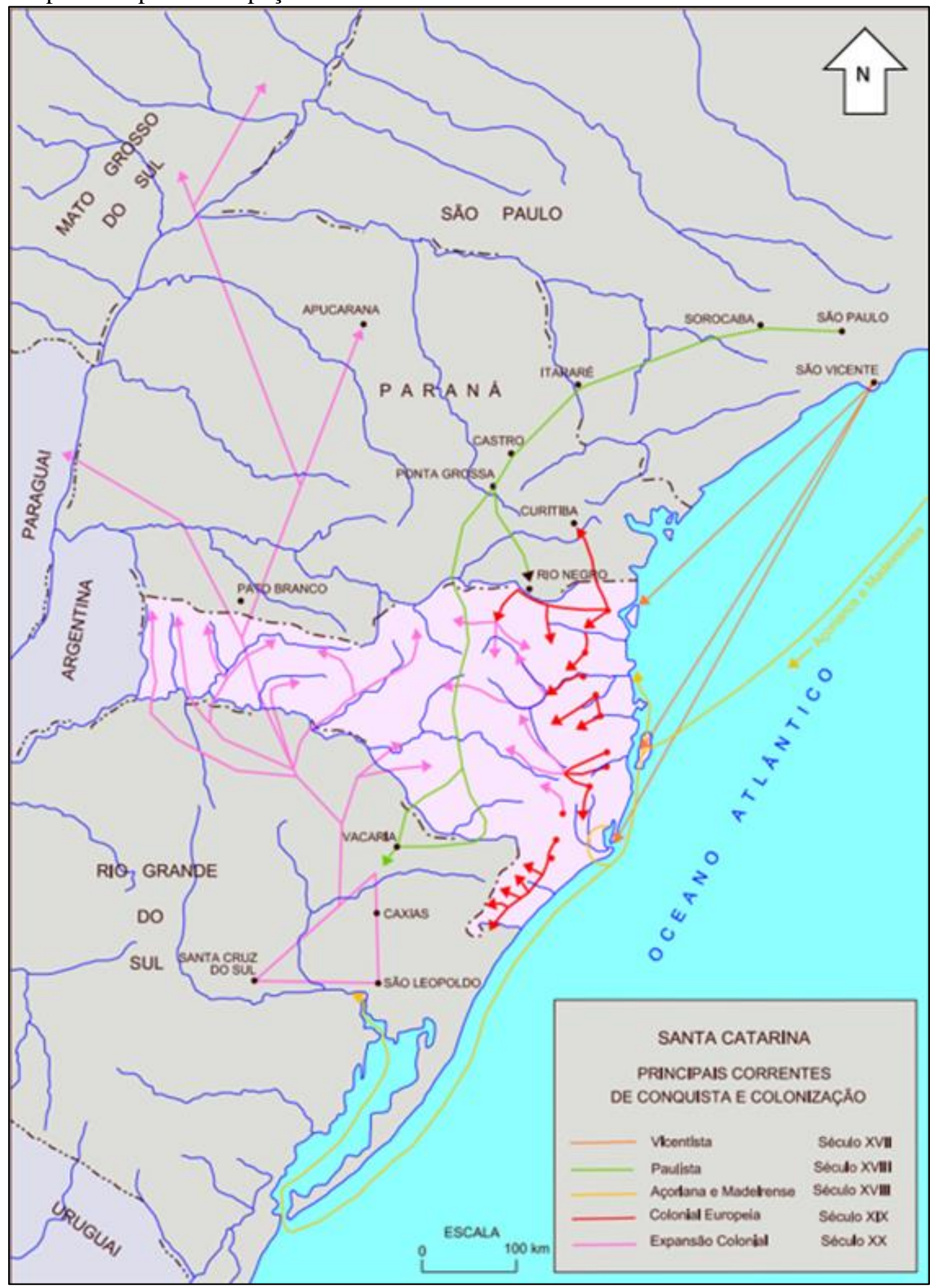

Fonte: Adaptado de Mamigonian (1958). Mapa organizado por Carlos Augusto Figueiredo Monteiro e desenhado por Odair Silva. 
Dando ênfase ao processo de ocupação do Oeste catarinense, vale salientar que ao derrubar a mata, as madeiras nobres comercializadas principalmente com a Argentina, não eram a única riqueza extraída. Pertile (2008) afirma que concomitantemente à extração da madeira, também ocorreu a extração e comercialização da erva-mate, que da mesma forma que a madeira, fazia parte da vegetação natural da região. A erva-mate, além da colheita, precisava passar por um processo de beneficiamento antes da comercialização, sendo que era vendida principalmente aos tropeiros, fazendeiros e pequenos estabelecimentos comerciais localizados próximos às áreas de extração. Em 1920, a erva-mate chegou a representar $27 \%$ das exportações totais de Santa Catarina, com a maior parte desse volume também comercializado com a Argentina (VON DENTZ e ESPÍNDOLA, 2019b).

O período econômico da madeira e da erva-mate foram importantes não só como principal fonte de renda da época, mas como atividades que serviram de base para as transformações que ocorreram nos anos seguintes; ou seja, são produtos que serviram para uma acumulação de capital inicial, servindo mais tarde ao surgimento de outras atividades. Dessa maneira, pode-se dizer que a partir de 1940 teve início na região inúmeras atividades ligadas ao cultivo de diferentes culturas agrícolas e a criação de animais (suínos, bovinos, leite, galinhas). Essas atividades visavam principalmente a subsistência das famílias, mas também a comercialização do excedente produzido. Neste cenário, somam-se as políticas de governo de fomento a produção de alimentos, que contribuíram para a região em que a agricultura familiar predominou desde a sua ocupação (CAMPOS, 1987).

Neste sentido, em esfera federal e estadual, diferentes políticas de governo visaram modernizar as práticas agropecuárias, de modo que paulatinamente, sobretudo a partir de 1960, com a implementação de pacotes tecnológicos e ação das cooperativas surgidas num contexto em que a ação coletiva dos imigrantes que ocuparam a região se sobrepôs as ações individuais, visando os ganhos econômicos na compra de insumos e comercialização dos produtos - alterou-se a estrutura produtiva da região a partir do uso da máquina. Essa alteração só foi possível em função do uso do crédito subsidiado pelo governo no campo. Neste contexto, a chamada revolução verde ficou conhecida na literatura como uma marca da propulsão dos avanços na modernização da agricultura (GRAZIANO DA SILVA, 1998). 
Com a introdução das máquinas, atividades como plantio e colheita dos produtos, passaram a ser mais rentáveis e ocorrer com maior rapidez, o que permitiu aumentar as áreas plantadas e a quantidade de produtos colhidos (VON DENTZ e ESPÍNDOLA, 2019). Neste contexto, vele salientar que os avanços na agricultura do Oeste catarinense ocorreram em função do aumento do crédito subsidiado pelo governo, concedido exclusivamente para custeio das lavouras, via Sistema Nacional de Crédito Rural (SNCR). Além disso, outras políticas de alcance macroeconômico almejavam que o Brasil não mais dependesse do mercado externo para suas atividades produtivas, dentre elas, a agropecuária. A política de substituição de importações, portanto, com a presença marcada do Estado, contribuiu significativamente para que o Brasil não mais dependesse do mercado externo para obter produtos agropecuários. Neste cenário, alinhado à "vocação" agrícola da região, o Oeste catarinense, desde sua ocupação, acabou se diferenciando no setor agroalimentar e se consolidando na produção de diferentes agronegócios ${ }^{3}$.

Vale frisar que esse processo de modernização ocorreu de maneira desigual e em diferentes níveis de tecnificação das pequenas, médias e grandes unidades produtivas (GRAZIANO DA SILVA, 1998). No entanto, a característica do desenvolvimento, de qualquer que seja o setor econômico, no modo capitalista de produção, terá desajustes como a desigualdade a serem considerados. Dessa maneira, no Oeste catarinense, os agricultores que tiveram maiores condições de se modernizar e ampliar suas atividades produtivas ou de investir na industrialização de seus produtos, foram aqueles mais capitalizados e com maior poder individual de ter acesso ao crédito (VON DENTZ e ESPÍNDOLA, 2019).

Assim, há outros pontos a serem destacados nesse conjunto de fatores, isto é, a tecnificação dos agronegócios do Oeste catarinense mudou muito, para melhor, a qualidade e as quantidades de produtos produzidos. No entanto, tratou-se de uma modernização que visou a todo momento a entrada do capital na região pela via dos diferentes agronegócios. Como consequência, nos dias de hoje, é impossível trabalhar na

\footnotetext{
${ }^{3}$ Diferentemente de uma vasta bibliografia que define agronegócio apenas ao que está ligado à produção de commodities e ao tamanho da área produtiva, definem-se, aqui, os agronegócios como uma cadeia produtiva "que envolve desde a fabricação de insumos, passando pela produção nos estabelecimentos agropecuários, pela transformação e pelo seu consumo final" (CONTINI et al., 2006, p. 6).
} 
agricultura sem o uso do capital. Por essa razão, pode-se notar no Oeste catarinense que os agronegócios se desdobraram numa associação entre a integração das unidades produtivas e às redes de produção locais e extralocais (VON DENTZ e ESPÍNDOLA, 2019). Tal sistema de integração se encarregou do comércio, logística e fornecimento de insumos de produtos industrializados, de maneira adequada às demandas e exigências dos mercados consumidores nacional e internacional de alimentos processados.

Contudo, os efeitos que atualmente são conhecidos da modernização da agricultura, isto é, crescimento na quantidade e qualidade da produção, aumento de área cultivada e de produtividade, instalação de complexos agroindustriais na região, dentre outros, só foram possíveis de se efetivarem em virtude da atuação do Estado nesta região. O Programa Nacional de Fortalecimento da Agricultura Familiar (PRONAF), que tem o papel de distribuir crédito subsidiado aos agricultores, foi e vem sendo um dos principais responsáveis por essas mudanças. Neste sentido, dada região onde diferentes agronegócios emergiram, sobretudo após os anos 2000, no item que segue será melhor analisado o papel que o Pronaf desempenhou na região, sobretudo na dinâmica geoeconômica e no progresso técnico dos agronegócios.

\section{O PAPEL dO PRONAF NA GEOECONOMIA E NO PROGRESSO TÉCNICO DOS AGRONEGÓCIOS DA REGIÃO OESTE CATARINENSE ${ }^{4}$}

Em sua obra sobre a questão agrária, Kautsky $(1980)^{5}$ já assinalava que sem aplicação de capital não há como realizar atividades ligadas a agricultura. Hoje sabe-se que isso serve não apenas para a agricultura, mas também para a pecuária e para qualquer que seja o setor produtivo da economia. Nos agronegócios, especialmente, qualquer que seja a atividade desenvolvida, o dispêndio de capital é ligeiramente necessário e irreversível. No entanto, os produtores dos agronegócios, por si só, não logram a acumulação de capital necessária para que as atividades produtivas sejam executadas integralmente. O mesmo ocorre em outros setores da economia, como no industrial e no

\footnotetext{
${ }^{4}$ Quando se fala em região Oeste catarinense refere-se à mesorregião geográfica do Oeste catarinense delimitada pelo IBGE.

${ }^{5}$ A primeira edição sistematizada e publicada em português da questão agrária de Kautsky ocorreu em 1972 pela editora Portucalense. No entanto, o livro foi publicado pela primeira vez em 1899, durante o congresso do partido social democrata alemão, em Frankfurt.
} 
de comércio e serviços. Assim, a intervenção do Estado no desprendimento de capital, em forma de crédito, para a agropecuária, historicamente foi fator determinante para que a estrutura produtiva do setor pudesse se desenvolver.

No caso do Brasil, há valores despendidos pelo Estado que financiam a agricultura de grande escala, através do chamado Plano Safra; e há valores dependidos pelo Estado para financiar a agricultura de pequena escala, através do (PRONAF). Na agricultura de grande escala, o financiamento passou por forte crescimento no período 2003-2014, quando variou de $\mathrm{R} \$ 72,7$ bilhões para $\mathrm{R} \$ 198,1$ bilhões. Na agricultura de pequena escala também ocorreu forte crescimento do crédito no mesmo período mencionado, embora menos expressivo. Em 2003 o valor total despendido pelo Estado via Pronaf foi de $\mathrm{R} \$ 5,06$ bilhões tendo alcançado a marca dos $\mathrm{R} \$ 24,6$ bilhões no ano de $2014^{6}$. Na Figura 1 é possível analisar a evolução do crédito concedido via Pronaf no Brasil, desde a segunda metade da década de 1990, quando o programa foi criado, até 2017.

\footnotetext{
${ }^{6}$ Não será entrado na discussão acerca da diferenciação de valores entre o Plano Safra e o Pronaf, embora seja sabido da disparidade no financiamento estatal para com a agricultura de grande e de pequena escala.
} 
Figura 1: Evolução do crédito do Pronaf no Brasil (valores constantes em reais, 19962017).

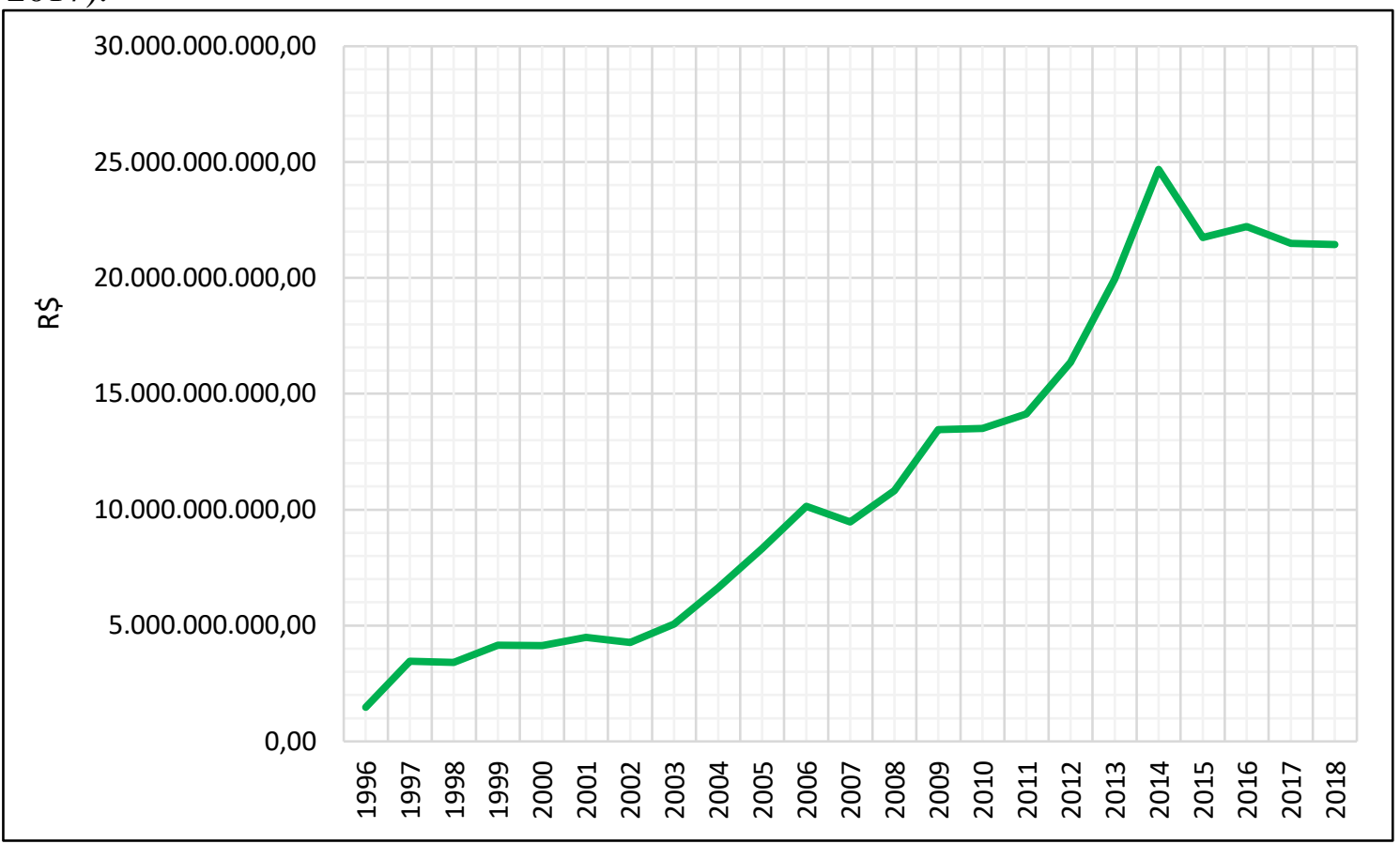

Fonte: Banco Central do Brasil ${ }^{7}, 2018$.

Conforme aponta a Figura 1, desde a criação do Pronaf, em 1996, houve um crescimento consecutivo do crédito disponibilizado à agricultura de pequena escala no Brasil, com destaque para o período 2003-2014, anteriormente mencionado, no qual ocorreu o crescimento mais expressivo do montante de crédito disponibilizado à agricultura familiar. A partir de 2014 nota-se, pela primeira vez desde a criação do programa, uma queda importante nos valores repassados aos agricultores via Pronaf. Essa queda se deu, dentre outros motivos, pela crise econômica na qual o Brasil entrou de 2015 em diante, de maneira que a economia do país, até os dias de hoje, encontra dificuldades para voltar a crescer.

O orçamento do Pronaf é muito importante para os agronegócios ligados à agricultura de pequena escala no Brasil pois, em regiões onde predomina as pequenas propriedades, torna-se economicamente inviável qualquer tipo de produção agropecuária sem alguma espécie de financiamento subsidiado. Dessa maneira, vale de pronto afirmar que muito dos avanços ocorridos na agropecuária brasileira de pequena escala da última década se deve, não somente, mas principalmente ao crescimento da concessão de crédito.

\footnotetext{
${ }^{7}$ Dados disponibilizados pelo Departamento de Regulação, Supervisão e Controle das Operações do Crédito Rural do Banco Central do Brasil.
} 
O Pronaf, por sua vez, tem sido o programa que mais garantiu possibilidades de produção e transformação da produção agropecuária de pequena escala no Brasil. Conforme aponta Mattei (2014), é inegável o fato de que hoje o Pronaf se traduz, em todo o Brasil, numa das principais políticas públicas de incentivo e estímulo ao desenvolvimento da pequena produção agropecuária, dando vez e voz a um segmento produtivo que historicamente foi deixado de lado. Somente em razão disso, o segmento social dos produtores rurais de pequena escala adquiriu uma importância econômica no período recente.

Em Santa Catarina - especialmente na região Oeste, recorte espacial de análise neste artigo - há forte predomínio de pequenas propriedades rurais onde, portanto, o papel do Pronaf foi e vem sendo fundamental. Embora seja o menor da região Sul do Brasil em extensão territorial e o que menos recebeu recursos em termos quantitativos se comparado ao Paraná e ao Rio Grande do Sul; detém uma parcela significativa do crédito do Pronaf em relação aos estados paranaense e gaúcho, considerando o período 2003 2018 (Figura 2). Isso ocorre em razão do fato de que, assim como no Paraná e no Rio Grande do Sul, em Santa Catarina, sobretudo a região Oeste, há o predomínio de pequenas propriedades rurais, isto é, agricultura de pequena escala. Por sua vez, essas características, alinhadas com outros fatores, possibilitam que uma parcela significativa do crédito do Pronaf da região Sul do Brasil seja aplicada em SC. Na Figura 2 é possível analisar os quantitativos de valores que foram aplicados em cada estado da região Sul do Brasil no período 2003-2018. 
do Pronaf foram criadas para beneficiar em maior percentagem os agricultores do Sul do Brasil; mas acabaram beneficiando mais em função do padrão de tecnificação e capitalização dos agricultores do Sul do Brasil, além da capacidade de buscar o crédito junto a um maior número de bancos e cooperativas alocadas nesta região. Nas outras regiões do Brasil, sobretudo nas regiões Norte e Nordeste, isso não se deu da mesma forma.

Em 2003, Santa Catarina foi responsável por 18,27\% de todo o crédito do Pronaf da região Sul do Brasil. Em 2018, esse percentual representou 24,13\%. Isso significa dizer que principalmente o Rio Grande do Sul, mas também o Paraná, embora os valores do Pronaf tenham crescido no período mencionado nesses estados, perderam porcentagem de participação, em termos de montante de crédito do Pronaf, em relação ao estado de SC. Essa constatação, no entanto, não permite afirmar que todo o estado foi beneficiado de forma homogênea pelo financiamento da agricultura de pequena escala via Pronaf. Por outro lado, desde a criação do Pronaf a adesão de SC pelo programa foi imediata, de modo que no ano da sua implantação, em 1996, dos 295 municípios de Santa Catarina, 248 usaram recursos do Pronaf.

Esses números demonstram a importância da agricultura de pequena escala no estado, de maneira que em 2011 todos os municípios do estado foram contemplados pelos recursos do Pronaf. Neste sentido, conforme apontam Fossá, Comerlatto e Piovezana (2015), desde que o Pronaf foi criado, a região Oeste catarinense foi a mais beneficiada pelo programa no estado de SC. Em 2012, 61,01\% dos desembolsos realizados via Pronaf no estado de SC se concretizaram na região Oeste; sendo que do total de contratos celebrados, em 2012, a mesorregião Oeste catarinense foi responsável por $64,76 \%$ do total estadual. Por conseguinte, Fossá, Comerlatto e Piovezana (2015) relatam que em 2012, dos dez municípios de Santa Catarina com maior percentual de volume de crédito contratado, nove pertenciam ao Oeste do estado: Palmitos (2,93\%),

de produtividade e à elevação da renda da família); 6) Pronaf Jovem (financiamento a agricultores e produtores rurais familiares, pessoas físicas, para investimento nas atividades de produção, desde que beneficiários sejam maiores de 16 anos e menores de 29 anos entre outros requisitos; 7) Pronaf Microcrédito - financiamento a agricultores e produtores rurais familiares, pessoas físicas, que tenham obtido renda bruta familiar de até R $\$ 20$ mil, nos 12 meses de produção normal que antecederam a solicitação da Declaração de Aptidão ao PRONAF -DAP); 8) Pronaf CotasPartes (financiamento para integralização de cotas-partes por beneficiários do Pronaf associados a cooperativas de produção rural; e aplicação pela cooperativa em capital de giro, custeio, investimento ou saneamento financeiro). 
Chapecó (1,88\%), Cunha Porã (1,87\%), Guaraciaba (1,83\%), Concórdia $(1,62 \%)$, Pinhalzinho (1,56\%), São José do Cedro (1,55\%), Videira (1,45\%) e Itapiranga (1,43\%). Esses nove maiores municípios de crédito via Pronaf concentraram, no ano de 2012, cerca de $16 \%$ do total de recursos destinados ao estado de SC, o que em termos de valores, representou cerca de 340 milhões de reais.

Quando a análise é ampliada para os 50 maiores municípios contratantes dos recursos do Pronaf, a concentração dos recursos atingiu 51,03\%, o que representou em 2012, mais de 1 bilhão de reais (BACEN, 2017). Por outro lado, dos 50 municípios com menor participação na contratação de Pronaf, a representação foi de apenas 1,65\% do valor total estadual, sendo que nenhum deles pertencia à região Oeste do estado (FOSSÁ, COMERLATTO e PIOVEZANA, 2015). Em razão desses dados, torna-se possível afirmar que essa concentração de recursos do Pronaf no Oeste catarinense, posicionou a agricultura de pequena escala como um dos mais, se não o mais, importante segmento produtivo da região. Ao mesmo tempo, a concentração de recursos do Pronaf no Oeste do estado reforça sua importância enquanto política pública; haja vista que oportuniza vias de financiamento aos agricultores, possibilidades concretas que podem melhorar a qualidade de vida e de trabalho deles. Além de ser a possibilidade real de investimento e desenvolvimento da agricultura de pequena escala na região. Na Figura 3 é possível observar a evolução dos recursos do Pronaf na região Oeste catarinense no período 19962012. 
Figura 3: Evolução dos recursos do Pronaf no Oeste catarinense (1996-2012 ${ }^{10}$ ).

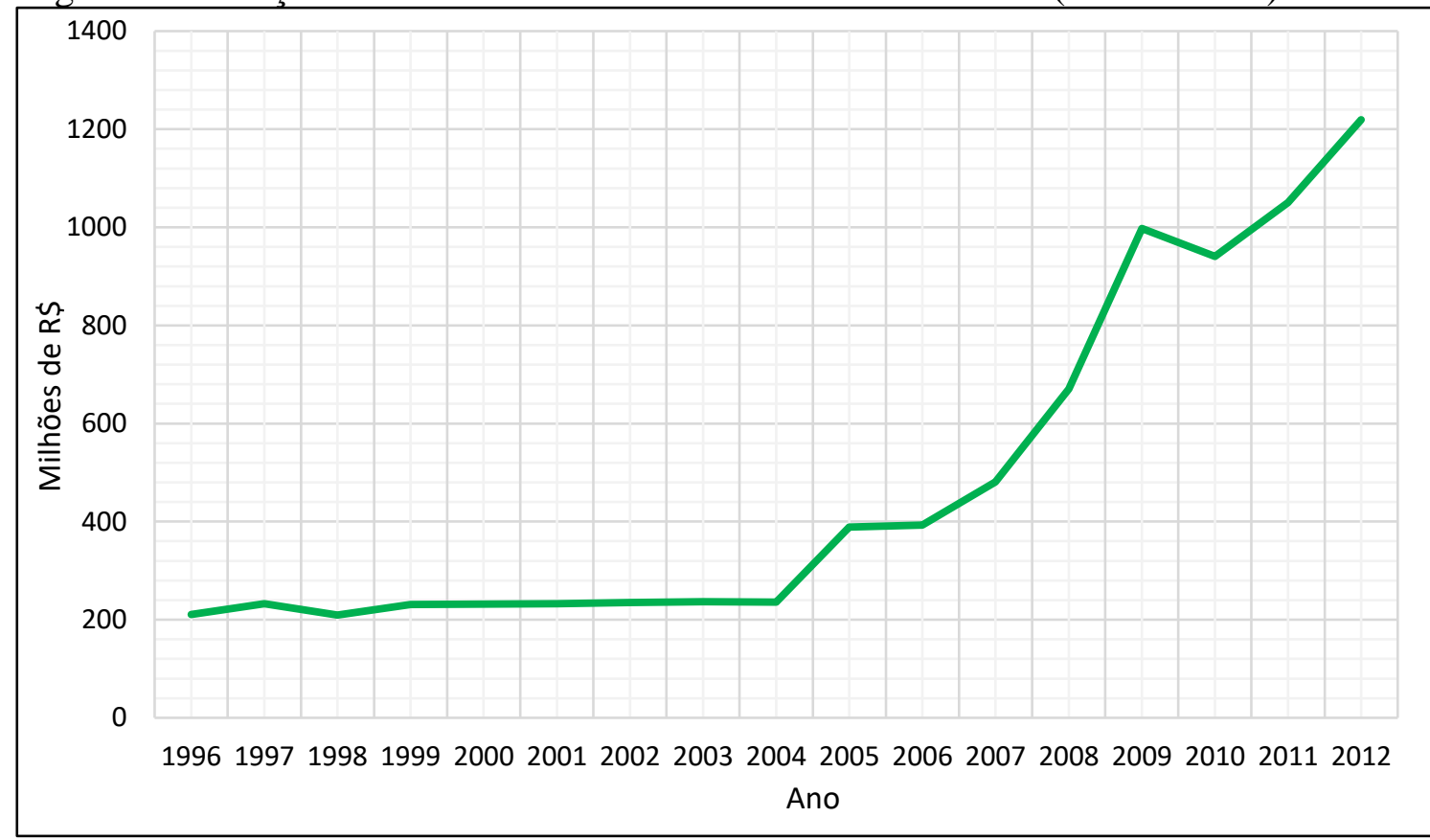

Fonte: Banco Central do Brasil. Organização dos autores.

É importante considerar que em termos de abrangência regional, todos os 118 municípios da mesorregião Oeste catarinense foram contemplados com o crédito do Pronaf em 2012. Ao mesmo tempo, vale chamar atenção para o forte crescimento no montante de crédito transferido para a região depois de 2004, sendo que neste ano o crédito do Pronaf era de aproximadamente 220 milhões de reais na região, tendo atingido a marca dos 1,23 bilhões de reais em 2012. No período 2004-2012, o crescimento do crédito do Pronaf no Oeste catarinense foi de aproximadamente $550 \%$, o que contribuiu significativamente para consolidar a região numa das maiores produtoras dos agronegócios do estado de SC, sobretudo nos de origem animal (suínos, aves e leite). Em 2012, o valor médio dos contratos da região Oeste catarinense foi de aproximadamente $\mathrm{R} \$ 13,2$ mil, ficando um pouco abaixo da média estadual ( $\mathrm{R} \$ 14,04$ mil) e um pouco acima da média nacional (11,3 mil) (FOSSÁ, COMERLATTO e PIOVEZANA, 2015). A média do valor dos contratos da região Oeste catarinense é menor que a média do estado de São Catarina em razão do grande número de contratos com baixo valor na região Oeste do estado. Por outro lado, é possível afirmar que muitos agricultores foram beneficiados pelo

${ }^{10}$ Conforme disponibilidade dos dados nas planilhas do Banco Central do Brasil, 2012 foi o último ano em que é possível acessar os dados por mesorregião. 
Pronaf. Em 2012, por exemplo, foram celebrados mais de 92 mil contratos no Oeste catarinense (FOSSÁ, COMERLATTO e PIOVEZANA, 2015).

Paralelamente ao significativo aumento do crédito do Pronaf no Oeste catarinense, no estado de SC e no Brasil, Espíndola (2016) aponta que de 2003 até 2016, as distintas cadeias produtivas dos agronegócios passaram por um dos maiores períodos de expansão da produção já vividos no Brasil. Nos quatro primeiros anos da década de 2000, o PIB brasileiro cresceu em média 2,3\% ao ano, ao passo que o PIB dos agronegócios cresceu 4,2\% ao ano no Brasil (CEPEA, 2015). Esse crescimento também pode ser visualizado na produção dos diferentes agronegócios do Oeste catarinense. Conforme aponta a Figura 4, o valor bruto da produção (VBP) dos principais agronegócios da região tiveram crescimento significativo no período 2003-2016, com destaque para os agronegócios de leite e $\operatorname{soja}^{11}$. O segmento de trigo apresentou crescimento mais tímido e o fumo apresentou decréscimo, em boa medida, em função de os setores de soja, leite, frangos, suínos e bovinos terem tomado o espaço do fumo.

\footnotetext{
${ }^{11}$ Vale ressaltar que o agronegócio do milho também teve forte crescimento no VBP, mas não é contabilizado pelo IBGE como milho, haja vista que antes da colheita desse produto, grande parte dele é transformado em silagem para alimentação da bovinocultura de leite principalmente no período de inverno. Essa parte da produção não é contabilizada no agronegócio do milho e sim no de leite.
} 
Figura 4: Evolução do VBP dos principais agronegócios do Oeste catarinense (20032016) $)^{12}$.

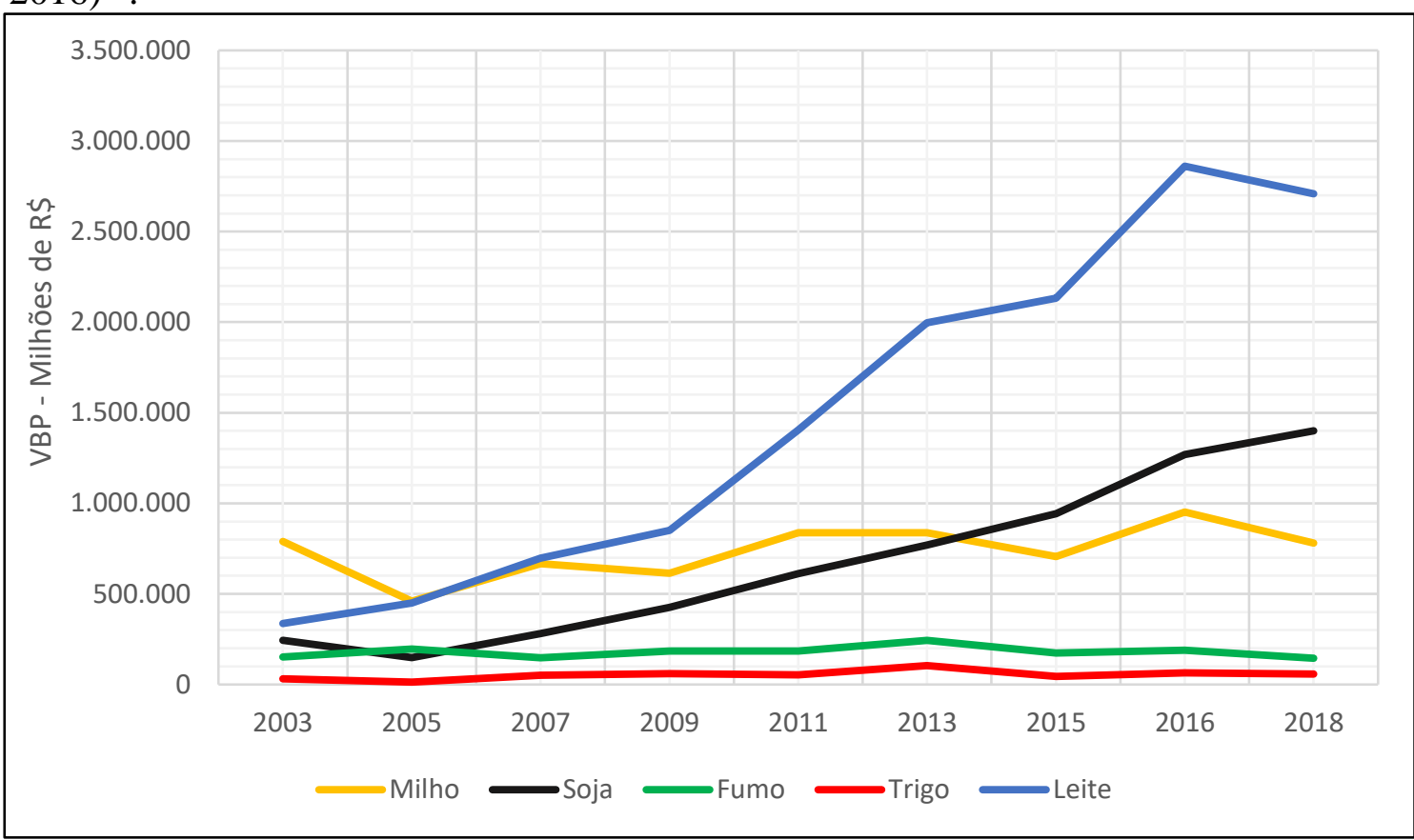

Fonte: Pesquisa agrícola municipal - IBGE, 2018.

Tendo em vista a inexistência de dados no Sistema Sidra do IBGE do VBP de frangos, suínos e bovinos, considerou-se na Figura 5 o efetivo de rebanho dos três segmentos produtivos citados. Com o dado do efetivo de rebanho é possível afirmar se ocorreu crescimento ou diminuição do segmento produtivo através de seus montantes de rebanho por segmento. Dessa forma, como aponta a Figura 5, é possível verificar crescimento, no período 2003-2018, nos rebanhos de frangos, bovinos e suínos. No caso do rebanho de bovinos, pode-se dizer que houve um crescimento ininterrupto no período analisado, tendo saído de 1,4 milhões de cabeças em 2003 para 2,1 milhões de cabeças em 2018, representando um crescimento de $66,6 \%$ no período. No caso do rebanho de suínos, nota-se uma considerável queda a partir de 2009 e uma recuperação a partir de 2015. Essa queda nos suínos se deu, em grande parte, em função da crise internacional de 2008 que afetou o setor de carnes, especialmente em países que, além de afetados pela crise econômica, passaram a ter maior exigência no setor de produção e processamento da carne suína. Ainda assim, a Figura 5 aponta que em 2003 o Oeste catarinense possuía

\footnotetext{
${ }^{12} \mathrm{Na}$ Figura 4 foram considerados somente os principais produtos da mesorregião Oeste catarinense.

VBP - Valor Bruto da Produção.
} 
um rebanho de 4,2 milhões de suínos, tendo alcançado 6,1 milhões em 2018; o que representa um crescimento de $68,8 \%$ no período analisado (Figura 5).

Figura 5: Evolução do efetivo de rebanho dos principais agronegócios de origem animal do Oeste catarinense (2003-2018).

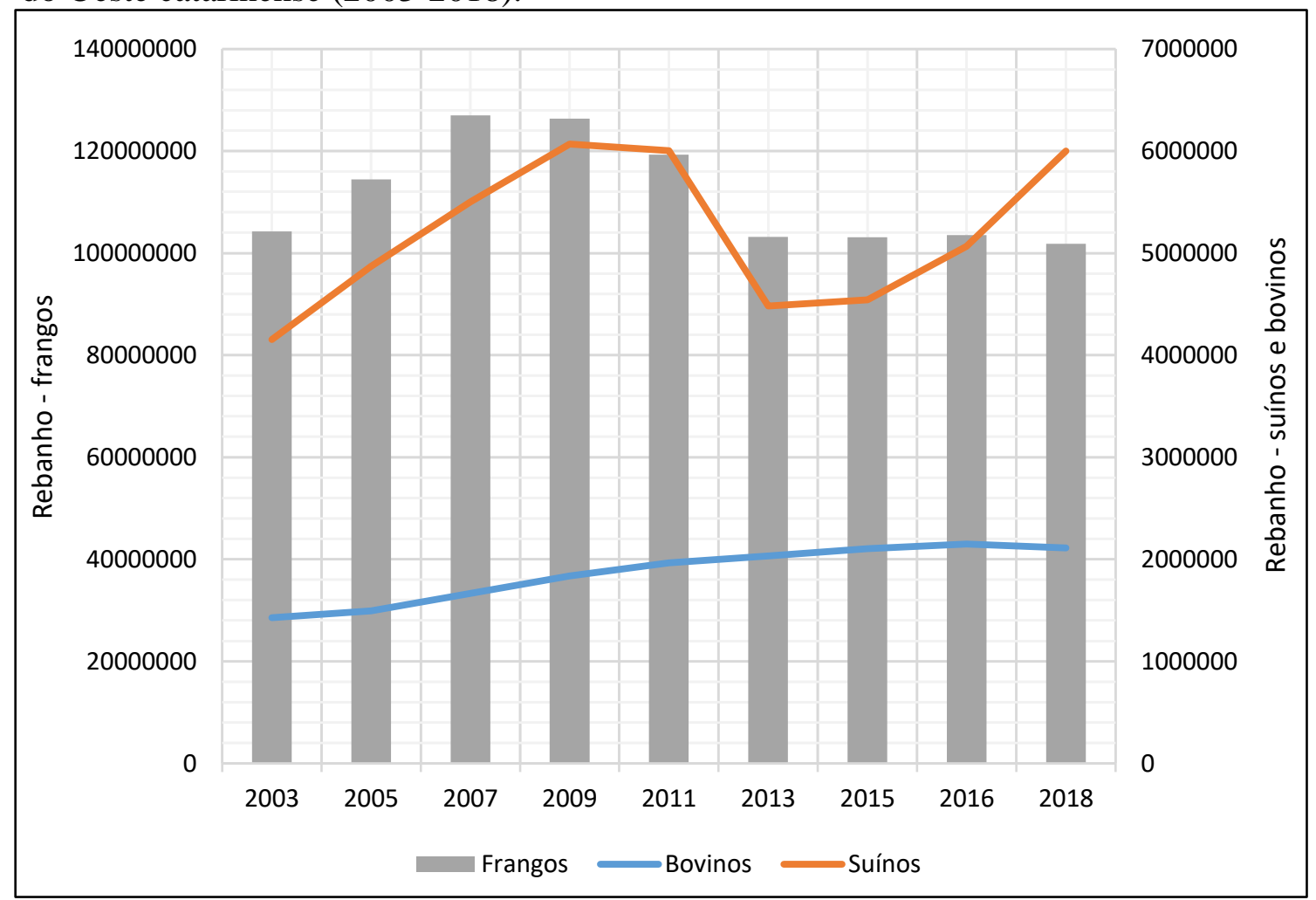

Fonte: Pesquisa pecuária municipal - IBGE, 2019.

Já para o rebanho de frangos (Figura 5), houve considerável crescimento de 2003 até 2007, quando atingiu 126 milhões de cabeças, uma diminuição de 2007 até 2013, quando atingiu 103 milhões de cabeças, e uma estagnação de 2013 até 2018, quando atingiu 102 milhões de cabeças. Dessa forma, no período 2003-2018 o rebanho de frangos no Oeste catarinense demonstrou uma variação negativa de $-1,9 \%$, ou seja, apesar da forte queda se manteve estável se considerado os números de 2003 em comparação com 2018. Ademais, mesmo com essa forte queda, o rebanho de frangos no Oeste catarinense é muito superior aos rebanhos de suínos e bovinos, em grande medida por se tratar de um tipo de produção animal que permite a criação em aviários que alojam até 30 mil frangos cada um. Nos outros segmentos (rebanho suíno e bovino), essa forte concentração de animais num mesmo espaço não é possível de acontecer. 
É importante frisar que, os dados levantados e analisados anteriormente sobre o Pronaf, interferem diretamente no crescimento e manutenção da produção dos diferentes agronegócios analisados nas Figuras 4 e 5; especialmente, os de soja, milho, trigo, leite, suínos, bovinos e frangos. Sem a evolução dos recursos concedidos via Pronaf não seria possível que os agricultores fizessem investimentos em suas propriedades, sobretudo de ordem técnica, para viabilizar o crescimento da produção que na maioria das vezes é intensiva em tecnologia. Para ter-se uma ideia de como o Pronaf foi e vem sendo importante para a dinâmica geoeconômica dos agronegócios do Oeste catarinense, foram selecionados os municípios da região que possuem mais de 700 estabelecimentos rurais (essa amostra permitiu considerar, na Figura 6, 37 dos 118 municípios da mesorregião), visando estabelecer uma relação entre o número de estabelecimentos rurais e o número de tratores por municípios. Em razão de esse levantamento ter ocorrido apenas com o Censo Agropecuário de 2017 não foi possível traçar uma série histórica desses dados. Ainda assim, permite considerar uma relação entre o número de estabelecimentos e o número de tratores por município.

Neste sentido, conforme é possível notar na Figura 6, ainda que os tratores não estejam presentes em todos os estabelecimentos rurais, há um número considerável de tratores em cada município, o que permite afirmar que uma parcela importante dos agricultores possui no trator uma possibilidade efetiva de realização das atividades com maior facilidade. Essa porcentagem significativa do número de tratores por município em relação ao número de estabelecimentos rurais foi alcançada, em grande medida, depois de 2003, momento em que o crédito rural alcançado pelos agricultores através do Pronaf atinge valores nunca vistos antes, como demonstrou a Figura 3. A partir das linhas de crédito específicas do Pronaf, muitos agricultores puderam comprar seus tratores para realizar as atividades de suas propriedades rurais, o que, consequentemente, refletiu num aumento significativo das quantidades e valores produzidos tanto na pecuária quanto na agricultura, conforme pôde-se notar nas Figuras 4 e 5.

No entanto, embora o avanço na tecnificação das atividades agropecuária a partir do número importante de tratores por municípios (Figura 6) tenha sido significativo, não quer dizer que o Oeste catarinense não tenha que continuar preocupando-se com essa política. Ainda há uma parcela grande dos agricultores que não puderam adquirir um trator para suas atividades. Esse fato pode servir aos que se dedicam à gestão pública em esfera municipal, estadual e federal; para que o crédito do Pronaf continue apresentado 
crescimento e para que as possibilidades de os agricultores financiarem tratores e outras máquinas importantes para seus processos produtivos continue se concretizando nessa região.

Figura 6: Número de estabelecimentos rurais e tratores por município selecionado da mesorregião Oeste catarinense $(2017)^{13}$.

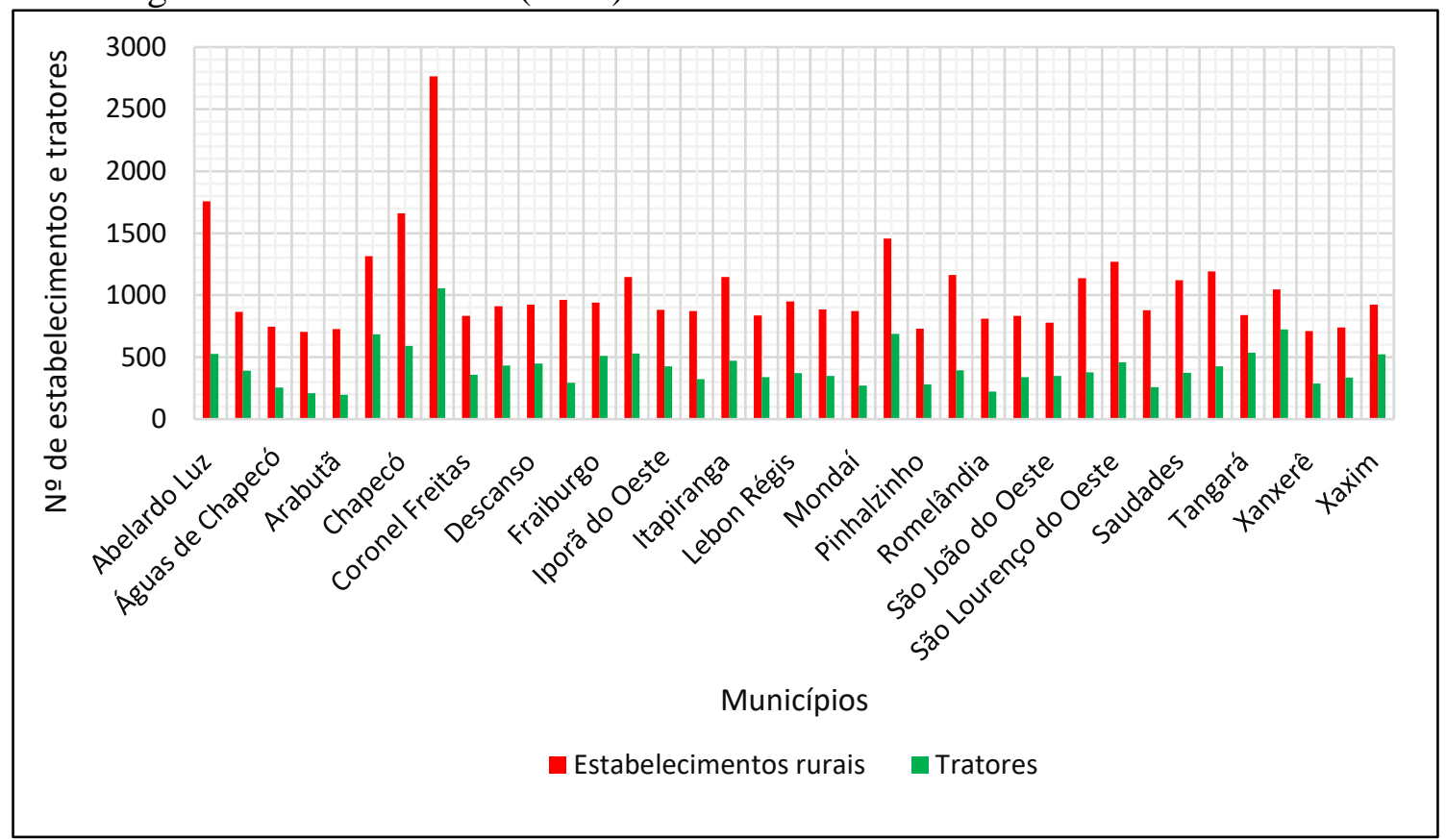

Fonte: Censo agropecuário (IBGE, 2017).

Com a presença marcante do Estado através de incentivos como o crédito do Pronaf, traduz-se a realidade da agricultura de uma região, e, neste caso, de um país, em possibilidades reais de investimento e compra de equipamentos, insumos e instrumentos que possam representar desenvolvimento dos agronegócios, dinamizando a geoeconomia e incentivando pessoas dessa área e de outras áreas a ver na agropecuária uma possibilidade real de retorno dos investimentos realizados. Neste sentido, o Oeste de Santa Catarina, embora tenha apresentado avanços inegáveis nos últimos anos, especialmente pós 2003 , ainda apresenta no setor agroalimentar muitas dificuldades a serem superadas. Dentre elas, pode-se citar que a região tem potencial para diversificar ainda mais sua produção, sobretudo nos setores de frutas, legumes e verduras - que ainda é pouco explorado. Por outro lado, há necessidade de continuar investindo nos setores já

\footnotetext{
${ }^{13}$ Devido ao grande número de municípios do Oeste catarinense (118 no total), para a Figura 6 foram selecionados somente os municípios que possuem mais de 700 estabelecimentos rurais.
} 
consolidados, como o de suínos, frangos, leite, soja e bovinos; tendo em vista que é preciso, tal como apontou Shumpeter (2017), que para que o desenvolvimento de uma estrutura produtiva de fato aconteça, seja despendido capital para pesquisa, inovação e tecnologia. Dessa maneira, seria possível inovar em processos produtivos e produtos finais derivados dessa produção.

Dito isto, cabe enfatizar que o papel do Pronaf nos avanços técnicoeconômicos, de aumento de produção, produtividade e área plantada, por exemplo, foi fundamental; pois somente a partir do momento em que os agricultores contaram com o crédito do Pronaf é que novas possibilidades de desenvolvimento da produção passaram a existir. Portanto, ainda que o Pronaf tenha seus problemas enquanto um programa de um país com dimensões continentais como é o Brasil, cabe frisar que para o Oeste de SC, se o programa não existisse suas características seriam agravadas do ponto de vista social e econômico, principalmente com uma possível maior concentração de renda, falta de jovens para continuar as atividades agropecuárias, no envelhecimento da população rural e na grande dificuldade de realizar as atividades de maneira disseminada pelo território regional.

\section{CONSIDERAÇÕES FINAIS}

A mesorregião Oeste catarinense, desde a sua gênese de ocupação e colonização, foi caracterizada pela presença de uma população que se manteve ligada a agricultura e a pecuária. Embora um ciclo inicial da extração da madeira e da erva-mate tenham sido as primeiras atividades econômicas da região, o cultivo agrícola e pecuário sempre esteve presente nas famílias que ocuparam os lotes da região desde a década de 1940. Dessa forma, diferentemente do que ocorre em outras regiões catarinenses, o Oeste catarinense se consolidou pela especialização produtiva ligada aos agronegócios.

Conforme Espíndola (1999), a passagem do complexo rural para o complexo agroindustrial no Oeste catarinense conferiu à região uma grande capacidade não apenas de produção pecuária e agrícola, mas também de transformar essa produção. Em razão disso, é comum encontrar complexos agroindustriais na região que transformam principalmente a produção de animais, leite e grãos. No entanto, o alcance da estrutura produtiva que se encontra hoje na região está diretamente atrelada ao papel do Estado. Historicamente, o Estado esteve presente através de diferentes formas de financiamento 
da produção, tanto em pesquisa e financiamento de plantas industriais, quanto em assistência técnica, extensão rural e financiamento das atividades produtivas dos agricultores.

Neste sentido, a partir da segunda metade da década de 1990, com a criação do Pronaf, um programa efetivamente voltado para a agricultura de pequena escala passou a vigorar na região. Os contratos e volumes de recursos contratados via Pronaf no Oeste catarinense, tal como pôde-se verificar no artigo, tiveram forte crescimento principalmente a partir da década de 2000. O dispêndio desses recursos permitiu que boa parte dos agricultores da região melhorassem suas estruturas produtivas adquirindo máquinas, sementes geneticamente melhoradas, animais geneticamente melhorados, preparando melhor o solo para plantio, melhorando a estrutura de aviários, chiqueirões, armazéns, dentre outros.

Em virtude da efetivação e do crescimento do crédito do Pronaf na região, atualmente o Oeste catarinense é responsável por cerca de $72 \%$ da produção estadual de grãos, $75 \%$ da produção estadual de frangos e suínos, 55\% da produção estadual de bovinos e em cerca de $72 \%$ da produção estadual de leite. Essa concentração da produção agroalimentar no Oeste do estado de Santa Catarina mostra que a região cumpre um papel estratégico na divisão regional do trabalho, com a capacidade de concentrar a produção estadual de alimentos, mas de maneira diversificada, haja vista que se tratam de diferentes agronegócios que se destacam na geoeconomia da região e de uma diversidade considerável de produtos derivados desses agronegócio. Para citar o exemplo do leite, é possível apontar produtos derivados como: iogurte, leite em caixa, leite em caixa desnatado, queijo muçarela, queijo tradicional, bebida láctea, dentre outros.

A concentração dessa produção e o forte crescimento da produção e da produtividade dos produtos, ocorridos nas últimas duas décadas, são decorrentes de inúmeros fatores. A preocupação neste artigo foi demonstrar como o Pronaf influencia nessa dinâmica produtiva e como sua ausência poderia acarretar sérias consequências para a região que é predominantemente marcada pela agricultura de pequena escala. Ademais, como demonstrado, o Pronaf, para a região, não significou apenas possibilidade de os agricultores produzirem, mas também a possibilidade de melhorar tecnicamente suas formas de produção, através da aquisição de tratores e maquinaria adequada para a produção agropecuária, por exemplo. 


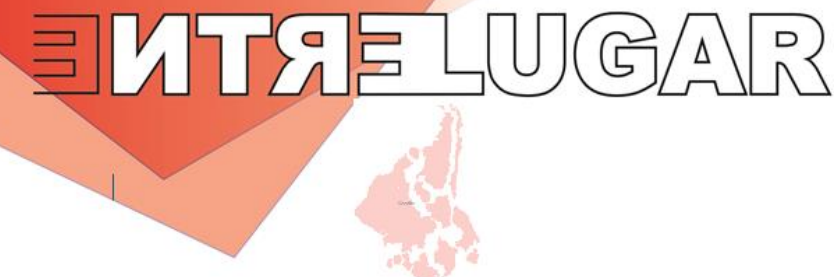

\section{REFERÊNCIAS BIBLIOGRÁFICAS}

BANCO DO BRASIL. Anuário de crédito rural. Brasília, 2017. Disponível em: https://www.bcb.gov.br/estabilidadefinanceira/creditorural. Acesso em: 18 set. 2019.

CAMPOS. Indio. Os colonos do Rio Uruguai: relação entre a pequena produção e a agroindústria no Oeste Catarinense. Campina Grande: UFPB, 1987. (Dissertação, Mestrado em Economia).

CEPEA. Centro de Estudos Avançados em Economia Aplicada. PIB do agronegócio. 2015. Disponível em: <http://www.cepea.esalq.usp.br/>. Acesso em: 16 out. 2016.

CONTINI, Elisio. et al. Evolução recente e tendências do agronegócio. Revista de Política Agrícola, Brasília, CONAB, ano XV, n. 1, jan.-fev.-mar. 2006, p. 5-28. Disponível em: <https://seer.sede.embrapa.br/index.php/RPA/article/view/475>. Acesso em: 10 out. 2019.

EPAGRI/CEPA. Instituto de Planejamento e Economia Agrícola de Santa Catarina. Síntese Anual da Agricultura Catarinense. 2018. Disponível em: <http://www.epagri.sc.gov.br>. Acesso em: 18 out. 2019.

ESPÍNDOLA, Carlos José. As Agroindústrias no Brasil: o caso Sadia. Chapecó. Grifos, 1999.

ESPÍNDOLA, Carlos José. Ciclo de crescimento da economia brasileira e desempenho do agronegócio catarinense. Geografia (Londrina), v. 25, p. 91-109, 2016

FOSSÁ, Juliano Luiz, COMERLATTO, Dunia e PIOVEZANA, Leonel. A participação de Santa Catarina no Programa Nacional de Agricultura Familiar (PRONAF). PRACS: revista eletrônica de humanidades do curso de ciências sociais da Unifap, Macapá, v. 8, n. 2, p. 37-50, jul./dez. 2015.

GRAZIANO DA SILVA, José. A nova dinâmica da agricultura brasileira. 2 ed. Unicamp, 1998.

IBGE. Pesquisa Agrícola Municipal. 2018. Disponível em: <https://sidra.ibge.gov.br/home/ipca15/brasil>. Acesso em: 15 nov. 2019.

IBGE. Produto interno bruto dos municípios: 2010 / IBGE, Coordenação de Contas Nacionais. Rio de Janeiro: IBGE, 2010. Disponível em: <https://biblioteca.ibge.gov.br/visualizacao/livros>. Acesso em: 23 out. 2019.

IBGE. Censo Demográfico, 2010. Disponível em: <https://censo2010.ibge.gov.br/sinopse>. Acesso em: 25 out. 2019.

KAUTSKI, Karl. A questão agrária. São Paulo: Proposta Editorial, $3^{\text {a }}$ edição, 1980. 
MAMIGONIAN, Armen. Habitat rural e urbano. In: SANTA CATARINA. Departamento Estadual de Geografia e Cartografia. Atlas Geográfico de Santa Catarina. Florianópolis: IBGE/DEGC, 1958.

MAMIGONIAN, Armen. As conquistas marítimas portuguesas e a incorporação do litoral de Santa Catarina. In: O mundo que o português criou. Recife: CNPq/Fjn, 1999.

MATTEI, Lauro. Evolução do crédito do pronaf para as categorias de agricultores familiares a e a/c entre 2000 e 2010. Revista Economia do Nordeste. Fortaleza, v. 45, n. 3, p. 58-69, jul/set., 2014.

PELUSO JUNIOR, Victor Antônio. Aspectos Geográficos de Santa Catarina. 1. ed. Florianópolis: FCC/EDUFSC, 1991. 284p.

PERTILE, Noeli. Formação do Espaço Agroindustrial em Santa Catarina: O Processo de Produção de Carnes no Oeste Catarinense. 2008. Tese (Doutorado em Geografia), Universidade Federal de Santa Catarina, Florianópolis.

SCHUMPETER, Joseph. Capitalismo, socialismo e democracia. São Paulo: editora da Unesp, 2017.

VON DENTZ, Eduardo; ESPÍNDOLA, Carlos José. Dinâmica produtiva da pecuária na mesorregião oeste catarinense: especialização e diversificação da produção no período de 2000 a 2017. Geosul, Florianópolis, v. 34, n. 71, p. 175-196, maio 2019. Disponível em: <https://periodicos.ufsc.br/index.php/geosul/article/view/1982-5153.2019v34n71p175>. Acesso em: 12 nov. 2019.

VON DENTZ, Eduardo; ESPÍNDOLA, Carlos José. Desempenho econômico-produtivo dos principais agronegócios da Mesorregião do Oeste Catarinense (2000-2016). Caderno de Geografia, Belo Horizonte, v. 29, n. 57, p. 334-350, abr. 2019. Disponível em: http://periodicos.pucminas.br/index.php/geografia/article/view/18481/14467. Acesso em 15 nov. 2019 b. 